\title{
A gramática alemã sob a perspectiva de seus aprendizes:crenças discentes e estratégias de aprendizagem
}

[The German grammar from its learners' perspective: learner beliefs and strategies]

Anna Carolina Schäfer ${ }^{1}$

\begin{abstract}
The purpose of this article is to analyze the results of a survey carried out with students of German as a foreign language, who were inserted in three different learning contexts in the city of São Paulo. The research aimed to investigate the beliefs of these learners concerning their process of learning the German language. The data, collected through questionnaires and interviews, revealed many of these beliefs, some related to, for example, the process of learning the German grammar. The results suggest a relationship between the beliefs and the choice of certain learning strategies. In the analysis stage, we sought to identify possible sources for the detected beliefs, as well as their potential effects on the learning process. In this article, some of the beliefs identified in the survey will be described and analyzed in relation to theoretical and methodological assumptions for teaching grammar in the didactic methods of foreign languages.
\end{abstract}

Keywords: learner beliefs; grammar learning; German as a foreign language

Resumo: O objetivo deste trabalho é divulgar e analisar os resultados de uma pesquisa realizada em três instituições paulistanas nas quais se ensina/aprende alemão como língua estrangeira. A pesquisa teve como objetivo geral investigar as crenças que alunos de língua alemã mantêm em relação a seu processo de aprendizagem. O corpus, coletado a partir de questionários e entrevistas, revelou muitas dessas crenças, referentes, por exemplo, à aprendizagem de gramática. Os resultados também apontam para a existência de uma relação entre as crenças e a adoção de determinadas estratégias de aprendizagem. Durante a análise, buscou-se identificar possíveis origens para as crenças detectadas, bem como os efeitos potenciais das mesmas sobre a aprendizagem da língua alemã. No presente artigo, algumas das crenças constatadas no estudo serão descritas e analisadas em relação a pressupostos teóricos e metodológicos da didática de línguas estrangeiras para o ensino de gramática.

Palavras-chave: crenças; aprendizagem de gramática; alemão como língua estrangeira;

\footnotetext{
${ }^{1}$ Mestranda do Programa de Língua e Literatura Alemã da FFLCH/ USP. Email: anna.schafer@ usp.br. O artigo é fruto de um projeto de iniciação científica desenvolvido sob orientação do Prof. Dr. José da Silva Simões e financiado pela FAPESP entre 2010 e 2012.
} 
SCHÄFER, A. C. - A gramática alemã sob a perspectiva de seus aprendizes "Quem nunca estudou alemão não faz ideia do quão estarrecedora é essa
língua. Certamente, nenhuma outra língua é tão desorganizada e
assistemática; tão escorregadia que foge ao alcance de qualquer um. Você
é jogado para lá e para cá, num desamparo total. E quando acredita ter
finalmente compreendido uma regra que promete um pedaço de terra
firme para repouso em meio ao tumulto alucinador das dez classes de
palavras, você vira a página e lê: "Salvo as seguintes exceções". É então
que, ao passar os olhos pela lista, você constata que há ali mais exceções
do que exemplos para aquela regra". (Mark Twain, Die schreckliche
deutsche Sprache, Trad. A.C.S.)

\section{Introdução}

Na citação reproduzida na epígrafe deste trabalho, o escritor norte-americano Mark Twain faz uma espécie de desabafo sobre seu processo de aprendizagem da língua alemã e exterioriza uma crença bastante comum acerca desse idioma: a de que alemão é um idioma difícil, cuja gramática exige esforços extremos para ser aprendida. Se, por um lado, essa "fama" da língua alemã pode desmotivar os interessados em aprendê-la, na medida em que a eleva a um patamar quase inatingível, por outro, é justamente essa suposta complexidade que atrai muitos aprendizes, interessados em dominar um idioma que os diferencie das outras pessoas. Afinal, como destaca BoHUNOVSKY (2005: 334), “a suposta impenetrabilidade do universo linguístico alemão assegura prestígio a quem tiver conseguido aprender essa língua, fazendo com que este seja visto como uma pessoa culta e distinta".

Tais crenças em torno da aprendizagem de alemão como língua estrangeira (ALE), entendidas aqui como "ideias, opiniões e pressupostos que alunos e professores têm a respeito dos processos de ensino/aprendizagem de línguas e que os mesmos formulam a partir de suas próprias experiências" (BARCELOS 2001: 73), são perceptíveis cotidianamente em cursos desse idioma. Elas podem ser explícitas, manifestando-se em falas como "para falar fluentemente alemão é necessário morar um período na Alemanha" e "aprender alemão exige muito tempo e dedicação", ou permanecer implícitas.

Em ambos os casos, as crenças dos aprendizes exercem forte influência sobre sua atitude durante o processo de aprendizagem. A atitude, enquanto variável afetiva da aprendizagem, pode ser compreendida como um estado mental do aprendiz que, ao ter origem em suas crenças e experiências prévias, é fortemente influenciada pelo contexto 
SCHÄFER, A. C. - A gramática alemã sob a perspectiva de seus aprendizes

social que o envolve (cf. GARDNER 1985: 8). Sob atitude entende-se aqui, portanto, a materialização das crenças. Diversos estudos já atribuíram às crenças, por exemplo, o poder de interferir no desempenho e na motivação (cf. HORWITZ 1988; DÖRNYEI 2005), de determinar a adoção de certas estratégias de aprendizagem (cf. BENSON \& LOR 1999; YANG 1999) e de criar barreiras à aprendizagem autônoma (cf. COTERALL 1995). Tendo em vista o referido potencial das crenças, o presente trabalho partilha do pressuposto lançado por ALMEIDA FILHO (1993: 22) que, ao colocá-las entre as forças operantes de seu Modelo de Operação Global do Ensino de Línguas, atribui-lhes a capacidade de influenciar o processo de aprendizagem como um todo.

As crenças que envolvem a aprendizagem da língua alemã constituíram o objeto de investigação de uma pesquisa que desenvolvi entre 2010 e 2012 em três contextos de aprendizagem desse idioma na cidade de São Paulo: a graduação em Letras/ alemão de uma universidade, uma escola alemã e um centro de estudo de línguas de escola pública (CEL). O corpus que será apresentado neste artigo foi coletado durante a pesquisa e é, portanto, originário desses três contextos. Os dados revelam crenças acerca dos mais diversos aspectos que envolvem a aprendizagem de uma língua estrangeira (LE). Dentre elas, destacaram-se aquelas relativas à aprendizagem da gramática ${ }^{2}$ alemã, que serão especificamente tematizadas neste trabalho.

$\mathrm{O}$ artigo inicia-se com a delineação de um panorama do ensino de gramática ao longo da evolução dos métodos de ensino de LE. Segue-se uma caracterização geral da pesquisa que deu origem ao corpus. Na seção destinada à apresentação dos resultados, algumas das crenças identificadas entre os três grupos de aprendizes que participaram do estudo são descritas e analisadas. Uma discussão dos resultados de pesquisa, que contrapõe os dados dos três contextos e lança um olhar sobre o tratamento dado às crenças em materiais didáticos atuais, encerra o trabalho.

\footnotetext{
${ }^{2}$ Tendo em vista as diversas definições de gramática existentes na literatura crítica, é necessário deixar claro que, por gramática, entende-se aqui a "descrição das regras, cujo conhecimento torna alguém capaz (i) de construir (oralmente ou por escrito) palavras, frases e textos corretos do ponto de vista morfológico e sintático, bem como equivalentes às suas intenções comunicativas, e (ii) de compreender tais palavras, frases e textos" (GÖTZE 2001: 187).
} 
SCHÄFER, A. C. - A gramática alemã sob a perspectiva de seus aprendizes

\section{1 ensino de gramática na aula de LE: um olhar diacrônico}

O ensino de gramática sempre esteve entre os temas mais controversos da didática de línguas estrangeiras. Ao observar a evolução dos métodos de ensino de LE, é possível perceber que o modo de ensinar gramática e o espaço reservado a ela nas aulas sofreram alterações significativas com o passar do tempo. Até mesmo a concepção de gramática mudou: se inicialmente os livros didáticos restringiam-se ao ensino da gramática normativa, hoje em dia cada há vez mais espaço para a variedade linguística.

Em nenhum método de ensino de línguas estrangeiras a gramática desfrutou de tanta importância quanto no método de gramática e tradução, desenvolvido na Europa no início do século XIX. Nele, ela constitui o objetivo maior da aprendizagem e é responsável por determinar a progressão de conteúdos: "Quem domina a gramática, domina a língua estrangeira" (NEUNER \& HunFELD 1993: 19). A concepção de gramática vigente é a normativa, com modelos extraídos de obras literárias consagradas.

O método direto, surgido no final do século XIX como reação ao método de gramática e tradução, traz a primeira grande reviravolta para o ensino de gramática. Nas aulas, a comunicação se estabelece apenas na língua-alvo, de modo que o aprendiz consiga deduzir intuitivamente as regras gramaticais ao imitar modelos de frases e diálogos (cf. NEUNER \& HunFELD 1993: 35). A variante linguística ensinada já não é a das grandes obras literárias: o destaque recai agora sobre a língua falada.

A preponderância da oralidade sobre a escrita se mantém nos métodos audiolingual e audiovisual, que atingiram seu auge nas décadas de 1950 e 60. Ambos são profundamente influenciados pela linguística estruturalista e pela psicologia behaviorista, de forma que a gramática é treinada pelos aprendizes sobretudo a partir de exercícios de repetição (pattern drills) e memorização. Esses métodos inauguram uma preocupação com a autenticidade do conteúdo ensinado. Procura-se apresentar as estruturas gramaticais tais quais inseridas em situações cotidianas.

Nos anos 70, surge a abordagem comunicativa, até hoje muito difundida no ensino de línguas estrangeiras. Ela é responsável por uma "virada pragmática" no ensino de línguas estrangeiras. A língua não é mais encarada como um sistema formal, mas sim, como instrumento da ação humana (cf. NEUNER \& HUNFELD 1993: 88). A gramática passa a ocupar um papel secundário e servil na aula de LE: ela deve servir 
SCHÄFER, A. C. - A gramática alemã sob a perspectiva de seus aprendizes

sempre às intenções e aos interesses comunicativos do aprendiz e ser apresentada a partir de um contexto próximo da realidade. Agora, o objetivo principal do ensino é desenvolver as habilidades (compreensão oral, fala, leitura e escrita) do aprendiz, para que o mesmo seja capaz de se comunicar na língua-alvo.

$\mathrm{Na}$ abordagem intercultural, que ganhou destaque na virada do século XXI e manteve muitas características da abordagem comunicativa, a gramática passa a ser apresentada a partir de textos, orais e escritos que contêm as estruturas a serem aprendidas. A reflexão sobre o processo de aprendizagem torna-se parte das aulas de LE: aprender a aprender é um dos objetivos mais buscados, bem como o desenvolvimento da competência comunicativa e de suas subcompetências, descritas no Quadro Europeu Comum de Referência para Línguas (CONSELHO DA EUROPA 2001).

Hoje em dia, o ensino de línguas estrangeiras vivencia, conforme constatam SPANNHAKE \& BOGACZ-GROß (2008: 235), os efeitos de uma "virada cognitiva". Muitas abordagens recentes propõem meios de desenvolver a conscientização linguística do aprendiz (language awareness), um dos conceitos centrais do ensino de línguas atual. As reflexões metalinguísticas são parte importante dessas abordagens, que visam, entre outras coisas, a uma sensibilização linguística interdisciplinar, à percepção da ligação entre língua e cultura e a uma compreensão holística do processo de aprendizagem (cf. LUCHTENBERG 2008: 115). O aprendizado gramatical é parte importante dessas abordagens, desde que os fenômenos gramaticais sejam, conforme alerta LUCHTENBERG (2008: 112), tratados de forma reflexiva:

Fenômenos gramaticais - estruturas, regras, modelos linguísticos - são fenômenos linguísticos dentre muitos outros, que podem, como tais, despertar a atenção dos aprendizes [...]. Refletir sobre a gramática implica, nesse sentido, em uma reflexão abrangente acerca da língua.

Sabe-se, entretanto, que em muitas salas de aula o ensino está muito distante das propostas mais recentes da didática de LE. A tradição dos métodos antigos ainda impera e o ensino continua pautado na transmissão descontextualizada e mecânica de regras gramaticais. Embora documentos oficiais, como os Parâmetros Curriculares Nacionais (BRASIL 1999), defendam o aprendizado gramatical como suporte para a compreensão leitora e para a comunicação, ainda é possível perceber diversos resquícios 
SCHÄFER, A. C. - A gramática alemã sob a perspectiva de seus aprendizes

das concepções e métodos tradicionais nas crenças que alunos e professores mantêm em relação ao processo de aprendizagem. Arraigadas no sistema cognitivo do aprendiz, essas crenças geram muitas vezes resistência frente a determinadas técnicas e estratégias de aprendizagem, provocando frustração e desmotivação. É o que revelaram os resultados do estudo empírico que deu origem a este artigo.

\section{Caracterização da pesquisa}

\subsection{Contextualização}

Os dados apresentados neste artigo foram coletados entre 2010 e 2012 em três contextos de aprendizagem da língua alemã na cidade de São Paulo. Os contextos - graduação em Letras (alemão), escola alemã e centro de estudo de línguas de escola pública - foram selecionados de modo a constituir um panorama de análise que representasse a diversidade de instituições que oferecem cursos de alemão na maior cidade brasileira.

O principal critério para a escolha dos informantes dentro de cada contexto foi a idade e o tempo de aprendizagem da língua alemã. Optou-se por priorizar participação de aprendizes que estudassem formalmente o idioma há mais tempo, pois apesar de as crenças terem um caráter dinâmico, podendo variar ao longo do tempo e dentro do mesmo espaço (cf. BARCELOS 2007: 114), esta pesquisa parte do pressuposto de que quanto mais essas crenças estão ancoradas em experiências prévias, mais estáveis elas são. Esclarecidas assim as razões para a adoção do critério "tempo de aprendizagem", na graduação a pesquisa foi realizada com alunos da última disciplina de língua alemã (Língua Alemã V) e, na escola alemã, com alunos do terceiro ano do ensino médio. Apenas no CEL o critério "tempo de aprendizagem" não pôde ser seguido. Devido ao número reduzido de aprendizes ali presentes, a pesquisa foi realizada com aprendizes de todos os estágios (I a VI, sendo que cada estágio corresponde a um semestre de estudos). Participaram da pesquisa aproximadamente 40 universitários, 25 alunos da escola alemã e 15 aprendizes do CEL.

Tendo em vista a importância dos fatores contextuais para a compreensão das crenças, buscou-se identificar e descrever, a partir da observação de aulas nas três instituições, alguns fatores que pudessem explicar o estabelecimento e consolidação de determinadas crenças, a saber: o programa institucional, o material didático utilizado, a 
SCHÄFER, A. C. - A gramática alemã sob a perspectiva de seus aprendizes

rotina do grupo, a experiência dos alunos com aprendizagem de línguas e as crenças do próprio professor de língua alemã ${ }^{3}$.

Foram observadas aproximadamente cinco aulas de língua alemã em cada um dos grupos que participou da pesquisa. Uma descrição detalhada dos contextos de pesquisa, construída tanto a partir de anotações de campo quanto de uma análise documental do plano de ensino de cada instituição, fez-se fundamental para uma análise coerente e embasada das crenças que emergiram deles, bem como para a inferência de possíveis implicações didáticas dessas crenças. No quadro abaixo, estão sintetizadas algumas informações acerca dos três grupos de informantes:

\begin{tabular}{|c|c|c|c|}
\hline Contexto: & Graduação & Escola alemã & CEL \\
\hline Idade média & 20-25 anos & 16-17 anos & 14-17 anos \\
\hline $\begin{array}{c}\text { Tempo médio de } \\
\text { aprendizagem de ALE }\end{array}$ & 2- 3 anos & 10 anos & $1-6$ semestres \\
\hline $\begin{array}{l}\text { Aulas de ALE: carga } \\
\text { horária semanal }\end{array}$ & $4 \mathrm{~h} / \mathrm{a}$ & $5 \mathrm{~h} / \mathrm{a}$ & $4 \mathrm{~h} / \mathrm{a}$ \\
\hline $\begin{array}{l}\text { Nível linguístico } \\
\text { aproximado }\end{array}$ & $\mathrm{B} 1 / \mathrm{B} 2$ & $\mathrm{~B} 2 / \mathrm{C} 1$ & $\mathrm{~A} 1 / \mathrm{A} 2$ \\
\hline Livro didático & $\begin{array}{l}\text { Schritte International } \\
5\end{array}$ & AusBlick 2 & Planet 1 ou 2 \\
\hline \multirow[t]{2}{*}{ Alemão como... } & $2^{\mathrm{a}} \operatorname{LE}(48 \%)$ & $1^{a} \operatorname{LE}(73 \%)$ & $2^{a} \operatorname{LE}(73 \%)$ \\
\hline & $3^{\mathrm{a}} \operatorname{LE}(36 \%)$ & $2^{\mathrm{a}} \mathrm{LE}(19 \%)$ & $3^{\mathrm{a}} \mathrm{LE}(20 \%)$ \\
\hline
\end{tabular}

Tabela 1: Descrição dos contextos de pesquisa

\subsection{Metodologia}

A metodologia desta pesquisa combinou técnicas das três abordagens adotadas em estudos sobre crenças, descritas por BARCELOS (2001): a abordagem normativa, em que as crenças são inferidas a partir de questionários do tipo escala Likert, a

\footnotetext{
${ }^{3}$ Também participaram da pesquisa os três professores que ministravam aulas de língua alemã nas turmas investigadas. Eles responderam a questionários e suas respostas foram contrastadas com as de seus alunos.
} 
SCHÄFER, A. C. - A gramática alemã sob a perspectiva de seus aprendizes

abordagem metacognitiva, que acessa as crenças a partir do autorrelato dos participantes da pesquisa em questionários e entrevistas, e a abordagem contextual, da qual a pesquisa de campo e análise do contexto de aprendizagem são parte fundamental. Assim concebida, a coleta de corpus junto aos aprendizes dividiu-se em três fases, que se diferenciam de acordo com o instrumento de pesquisa utilizado em cada uma delas: um inventário de crenças, um questionário aberto e entrevistas semiestruturadas, aplicados nessa ordem.

O inventário de crenças utilizado na primeira fase da coleta de corpus foi o Beliefs about Language Learning Inventory (BALLI). Elaborado por Elaine HoRWITZ (1988), ele é um questionário do tipo escala Likert: contém afirmações diante das quais os informantes devem se posicionar numa escala que vai de "concordo plenamente" a “discordo plenamente". Seus 34 itens acessam as crenças dos aprendizes em cinco áreas: dificuldade de aprendizagem de LE, aptidão para a aprendizagem de LE, natureza da aprendizagem de LE, estratégias de aprendizagem e comunicação e motivações e expectativas. Ao final da aplicação, obtivemos 92 inventários respondidos por aprendizes (45 da graduação, 31 da escola alemã e 16 do CEL). Os dados obtidos foram tabulados em forma de porcentagens.

A escolha do questionário BALLI como primeiro instrumento de levantamento de crenças deu-se pelo fato de ele permitir uma relativamente rápida percepção e visualização de onde estão as crenças mais problemáticas em cada contexto, a partir de uma tabulação numérica dos resultados. Tinha-se consciência, entretanto, de que uma pesquisa que tivesse como única fonte de dados os resultados do BALLI seria bastante deficiente, uma vez que este questionário estabelece previamente as categorias de análise e não permite que os sujeitos de pesquisa exteriorizem suas crenças utilizando suas próprias palavras e metáforas. Por esse motivo, optou-se por introduzir os outros dois instrumentos de coleta de dados, que permitem aos sujeitos avaliar o processo de aprendizagem em seus próprios termos e dão, dessa forma, mais propriedade às conclusões posteriores.

O segundo instrumento de pesquisa utilizado, o questionário aberto, foi elaborado durante a pesquisa com o intuito de aprofundar alguns tópicos que emergiram da análise preliminar dos resultados obtidos pelo BALLI. Esses questionários também foram utilizados para a obtenção de informações adicionais sobre os aprendizes (tais 
SCHÄFER, A. C. - A gramática alemã sob a perspectiva de seus aprendizes

como suas motivações, experiências prévias com a aprendizagem de línguas e as estratégias mais utilizadas por eles) e sobre o contexto de aprendizagem. Ele visou ainda ao levantamento de crenças específicas, não contempladas pelo inventário.

Responderam ao questionário 80 informantes, sendo 39 universitários, 26 alunos da escola alemã e 15 aprendizes do CEL. A tabulação dos resultados foi feita a partir do agrupamento de respostas pelo critério de convergência/ unidade de ideias. Algumas respostas típicas foram transcritas e, por fim, os dados foram quantificados em porcentagens.

$\mathrm{Na}$ última fase da coleta de corpus, foram realizadas entrevistas com dois alunos de cada contexto. $\mathrm{O}$ roteiro utilizado nas entrevistas foi confeccionado de modo a abordar de forma mais detalhada alguns pontos levantados pelos outros dois instrumentos. Ele se dividia em três partes. Na primeira, levantavam-se dados gerais sobre o entrevistado (idade, profissão, contato com a cultura alemã fora da sala de aula, experiência com aprendizagem de línguas etc.)

A segunda parte da entrevista visava eliciar crenças dos aprendizes acerca de alguns elementos específicos da aprendizagem de línguas. As palavras gramática, motivação, provas/avaliações, dicionário, livro didático, professor e alunos estavam registradas em pequenas placas de cartolina. Solicitava-se que os entrevistados retirassem uma placa de cada vez e discorressem livremente sobre aquele elemento e seu papel na aprendizagem de ALE.

A terceira e última parte do roteiro foi extraída com adaptações de LEFFA (1991: 59). $\mathrm{O}$ autor propõe o acesso às crenças de aprendizes por meio de uma narrativa com lacunas que devem ser completadas pelo entrevistado. $\mathrm{O}$ enredo adaptado girava em torno de duas jovens (uma brasileira e uma alemã) que se conhecem no Brasil e se tornam amigas. A brasileira resolve então aprender alemão para se comunicar melhor com a amiga. O entrevistado é convidado a opinar e dar "dicas" para a jovem seguir em seu percurso de aprendizagem da língua alemã.

O roteiro, elaborado de modo a abordar as crenças de forma indireta, mostrou-se bastante eficaz para aprofundar aspectos levantados pelas outras duas técnicas utilizadas e eliciar novas crenças. Todas as entrevistas foram gravadas e transcritas parcialmente. Para a transcrição, foram selecionados os trechos em que os aprendizes exteriorizavam 
SCHÄFER, A. C. - A gramática alemã sob a perspectiva de seus aprendizes

crenças ou estabeleciam alguma relação entre elas e outros fatores que atuam sobre o processo de aprendizagem.

Assim composto, o corpus permitiu um rastreamento eficaz de crenças dos informantes, que iam sendo confirmadas e exteriorizadas mais detalhadamente ao longo da coleta de dados. Como base teórica para a análise dessas crenças, recorreu-se a postulados recentes da didática de LE, tais como as diretrizes do Quadro Europeu Comum de Referência para Línguas (CONSELHO DA EUROPA, 2001).

\title{
3 Resultados da pesquisa: apresentação $e$ análise
}

Segundo o Quadro Europeu Comum de Referência para Línguas, o ensino formal de línguas estrangeiras na atualidade deve visar ao desenvolvimento da competência comunicativa do aprendiz, para que este seja capaz de interagir em realidades cada vez mais plurilíngues. Sob essa perspectiva, a competência comunicativa divide-se em três subcompetências (linguística, sociolinguística e pragmática), as quais tornam a se decompor em várias outras. A competência gramatical, enquanto subdivisão da competência linguística, é definida pelo documento da seguinte forma:

\begin{abstract}
A competência gramatical pode ser definida como o conhecimento dos recursos gramaticais da língua e a capacidade para os utilizar. Formalmente, a gramática de uma língua pode ser entendida como conjunto de princípios que regem a combinação de elementos em sequências significativas marcadas e definidas (as frases) [...] A competência gramatical é a capacidade para compreender e expressar significado, através da produção e do reconhecimento de frases e expressões bem construídas segundo estes princípios (ao contrário da sua memorização e reprodução) (CONSELHO DA EUROPA 2001: 161).
\end{abstract}

Dessa passagem, pode-se destacar três aspectos importantes, que deveriam guiar o ensino de gramática nas aulas de LE na atualidade:

1. Dispor de competência gramatical não significa apenas dominar as regras da língua, mas também saber utilizá-las para a comunicação;

2. A concepção de gramática que está em jogo não é a normativa, pautada na dicotomia certo x errado;

3. A competência gramatical não se constrói a partir de memorização e reprodução de regras, mas sim, a partir do uso. 
SCHÄFER, A. C. - A gramática alemã sob a perspectiva de seus aprendizes

Nas falas dos aprendizes de alemão entrevistados durante a pesquisa, é possível reconhecer ecos desses postulados. Informantes dos três contextos defenderam em suas entrevistas a importância da gramática como base para o sucesso de uma ação comunicativa:

C. (graduação): Eu gosto muito de gramática, mas eu sei que gramática não é tudo na língua. Então a gramática é necessária para conseguir se comunicar, consiga falar, consiga escrever, ler. Mas eu não acho legal focar só na gramática.

G. (escola alemã): Gramática é bom porque te ajuda na própria forma de falar. Se você sabe gramática você também sabe como montar as frases melhor [...] Eu acho bem útil porque me ajuda a formar frases em alemão e a aprender mesmo, na hora de escrever textos.

F. (CEL): A gramática... Ela é obviamente muito importante principalmente na hora de conversar com alguém. Se você não tem noção da gramática você não vai conseguir falar as coisas ou vai falar alguma coisa totalmente confusa para um habitante de lá ou para outra pessoa que fale alemão também.

Nessas passagens das entrevistas, os informantes demonstram ter uma concepção de gramática que não envolve unicamente o domínio de regras isoladas: o conhecimento das estruturas gramaticais é exposto por eles como pré-requisito para o funcionamento da ação comunicativa. Sem esse conhecimento, a comunicação seria inexistente ou extremamente falha, como aponta o aprendiz F., do CEL. Em outro ponto da entrevista, entretanto, esse mesmo aluno demonstra ter crenças associadas a uma concepção normativa de gramática. Em suas palavras, “é importante aprender a gramática, porque a gente precisa estudar o correto, o certo".

Nas crenças identificadas entre os informantes desta pesquisa, percebem-se com frequência tais contradições, que têm origem em dois discursos distintos. O primeiro deles é aquele presente nos manuais e livros didáticos mais recentes, que defendem um ensino de gramática contextualizado, reflexivo e voltado para a comunicação. $O$ segundo tipo de discurso vem se perpetuando há séculos no ensino de línguas e difunde ainda a ideia central do método de gramática e tradução: o ensino da gramática (normativa) como um fim em si mesmo. Tendo sempre em vista a existência dessa tensão, serão analisadas a seguir três crenças específicas, que foram amplamente constatadas dentre os informantes da pesquisa. 
SCHÄFER, A. C. - A gramática alemã sob a perspectiva de seus aprendizes

\subsection{Crença: "Alemão é uma língua difícil"}

Até o momento, não existem estudos empíricos que comprovem a maior dificuldade de certas línguas em relação a outras (cf. ROZENFELD \& VIANA 2011: 271). Entretanto, a opinião de que "alemão é uma língua muito difícil” tornou-se uma espécie de sensocomum e constitui hoje a crença mais comum acerca da língua alemã. Como era previsível, tal ideia foi constatada também entre os aprendizes e professores que participaram de nosso estudo. Em suas respostas ao inventário de crenças, $89 \%$ dos aprendizes da graduação, 84\% dos alunos da escola alemã e 56\% dos aprendizes do CEL classificaram a língua alemã como uma língua difícil ou muito difícil ${ }^{4}$. Dentre os professores, todos classificaram o idioma que ensinam como dificil.

Mas do que se está falando quando se diz que a língua alemã é “difícil”? Onde estão afinal, sob a perspectiva dos aprendizes, as maiores dificuldades dessa língua? Esboçar uma resposta a essa pergunta foi o objetivo de uma das questões dirigidas aos informantes ${ }^{5}$. Os resultados apontaram a gramática como uma das fontes de dificuldades de aprendizagem mais citadas nos três contextos: $62 \%$ dos informantes da graduação, 60\% da escola alemã e 50\% do CEL indicaram a complexidade da gramática alemã como um dos maiores empecilhos à aprendizagem da língua-alvo. Portanto, quando esses aprendizes mencionam a dificuldade da língua alemã, estão se referindo sobretudo à dificuldade enfrentada por eles para compreender e adquirir estruturas gramaticais.

Em um trabalho que problematiza a crença na dificuldade da língua alemã, BAUER (2003) chama a atenção para o fato de os próprios falantes desse idioma contribuírem para a consolidação de tal imagem, já que ela lhes assegura certo status. Nas palavras do autor, "quem convence os outros de que o caminho até o real domínio da língua alemã é longo, consegue mais facilmente se sentir competente e avançado, ou seja, dotado de vasta cultura intelectual” (BAUER 2003: 4). A disseminação da ideia de

\footnotetext{
${ }^{4}$ Respostas obtidas a partir do item 4 do inventário de crenças: A língua alemã é (a) uma língua muito difícil; (b) uma língua difícil; (c) uma língua de dificuldade mediana; (d) uma língua fácil; (e) uma língua muito fácil.

${ }^{5} \mathrm{Na}$ referida questão, os aprendizes eram convidados a assinalar, dentre as opções (a) gramática; (b) vocabulário; (c) pronúncia; (d) diferenças culturais e (e) ausência de dom para aprender línguas, até três respostas correspondentes às suas principais dificuldades para aprender alemão.
} 
SCHÄFER, A. C. - A gramática alemã sob a perspectiva de seus aprendizes

que alemão é uma língua complexa contribui, nesse sentido, para a construção de um determinado ethos para seus falantes.

Ainda segundo BAUER (2003: 4), as origens dessa crença remetem ao século XVIII, quando burgueses alemães intelectuais - os chamados Bildungsbürger - faziam do domínio do idioma um meio para se distinguirem das classes inferiores. Hoje em dia, o mesmo recurso continua a ser empregado com o objetivo de construir determinada imagem para o grupo de falantes de alemão. Seria, enfim, uma estratégia semelhante à utilizada pelos falantes de francês, ao sublinhar a beleza de seu idioma, ou pelos falantes de inglês, ao destacar a relevância deste enquanto língua franca (cf. BAUER 2003: 5).

Entretanto, tal estratégia termina muitas vezes por intimidar e, assim, desmotivar interessados em aprender a língua alemã. A desmotivação enquanto efeito dessa crença pôde ser claramente percebida ao longo da pesquisa. Na escola alemã, muitas queixas dos professores de ALE eram relativas à desmotivação de seus alunos para a aprendizagem. Quando questionados se gostavam de aprender alemão, $42 \%$ dos aprendizes responderam negativamente ${ }^{6}$. Dentre as justificativas mais citadas por eles estava justamente a suposta dificuldade da língua. Um dos alunos entrevistados nesse contexto declarou que provavelmente abandonaria definitivamente o estudo da língua alemã assim que concluísse o ensino médio (quando cessaria a "obrigação" de aprender o idioma), sob a seguinte justificativa:

G. (escola alemã): $\mathrm{O}$ vocabulário do alemão, a gramática do alemão é bem difícil, então... Para aprender alemão é difícil, então [a gente] acaba desistindo de aprender e vai fazendo só a obrigação, para tirar o mínimo possível para passar e acabou.

Ao gerar desmotivação e, em casos extremos, abandono do estudo da língua, a crença abordada neste item se perpetua e constitui obstáculos a uma maior democratização da língua alemã, que mantém cada vez mais sua imagem de acessível apenas a um seleto grupo de "corajosos", que gostam de enfrentar grandes desafios, bem como àqueles que teriam sido agraciados com o famoso "dom de aprender línguas".

\footnotetext{
${ }^{6}$ Porcentagem das respostas à pergunta "Você gosta de aprender alemão?", do questionário aplicado na segunda fase da coleta de corpus.
} 
SCHÄFER, A. C. - A gramática alemã sob a perspectiva de seus aprendizes

\section{2 "Aprender alemão significa aprender gramática"}

Outra crença bastante comum constatada entre os informantes desta pesquisa é a de que aprender um idioma é sinônimo de aprender novas regras gramaticais. Tal concepção foi constatada em maiores proporções na escola alemã e no CEL, onde, respectivamente, $67 \%$ e $60 \%$ dos aprendizes revelaram acreditar nessa soberania da gramática na aprendizagem de ALE. Dentre os estudantes de Letras, essa porcentagem foi significativamente menor: $23 \%^{7}$.

Tal crença denota uma percepção da natureza sistêmica da língua (cf. BARCELOS 2009: 166). Ela pode ser relacionada a um método de ensino de línguas bastante tradicional, já abordado neste trabalho: o método de gramática e tradução, segundo o qual aprender a língua estrangeira é, de fato, sinônimo de memorizar regras gramaticais. Essa concepção contradiz, entretanto, as tendências vigentes na didática de línguas estrangeiras desde a chamada virada comunicativa na década de 70, quando o foco do ensino voltou-se para a comunicação. Nessa nova perspectiva, a gramática passa a ser, conforme já ponderado anteriormente, apenas um dos diversos ramos da competência comunicativa a serem estimulados na aula de língua estrangeira.

Cruzando esses resultados com os de outra questão, é possível estabelecer uma relação entre as crenças dos aprendizes e suas experiências de aprendizagem. Quando questionados sobre quais atividades eram desenvolvidas com maior frequência em suas aulas de ALE, 97\% dos universitários, 79\% dos alunos da escola alemã e todos os aprendizes do CEL assinalaram a opção "exercícios gramaticais". Na graduação e no CEL, esta foi a atividade mais citada e na escola alemã, a terceira mais citada ${ }^{8}$. Assim, o peso conferido, na percepção dos alunos, ao treino de regras gramaticais durante as aulas contribui para a formação e para a consolidação da crença de que a aprendizagem da gramática é a parte mais importante da aprendizagem de línguas.

\footnotetext{
${ }^{7}$ As porcentagens correspondem à soma das respostas (a) concordo plenamente e (b) concordo ao item 19 do inventário de crenças: "Aprender alemão significa principalmente aprender regras gramaticais".

8 Resultado da tabulação das respostas à pergunta "Quais atividades são desenvolvidas com maior frequência nas suas aulas de alemão"? Os informantes podiam assinalar no máximo 7 atividades dentre (a) exercícios gramaticais; (b) músicas; (c) traduções; (d) memorização de diálogos; (e) filmes; (f) leitura em voz alta; (g) trabalhos em grupo; (h) produção de textos; (i) jogos; (j) cópias da lousa; (k) pesquisas; (l) ditados e (m) leitura silenciosa.
} 
SCHÄFER, A. C. - A gramática alemã sob a perspectiva de seus aprendizes

Ao abordar a relação entre crenças, experiências e ações, MiCCOLI (2010: 140) defende que o foco na experiência, entendida pela autora como "todos os acontecimentos relatados como significativos pelos quais professores e estudantes passam ao aprender uma língua em sala de aula" é tão importante quanto o foco nas crenças, de modo que

[...] as experiências anteriores deveriam receber mais atenção em vista de seu potencial para explicar ações e, até mesmo, dificuldades de professores ou estudantes em consequência da compreensão mais profunda dessas experiências e da maneira como podem influenciar o ensino e a aprendizagem (MICOLLI 2010: 144).

Ainda no que tange à relação entre crenças e experiências, os dados sugerem a existência de uma correlação entre as crenças dos aprendizes e de seus respectivos professores. Ao contrastar as respostas de ambos os grupos ao inventário de crenças, chegou-se a uma porcentagem de respostas equivalentes (casos em que a resposta do professor é igual à da maioria dos alunos) de $82 \%$ na graduação, $80 \%$ na escola alemã e $67 \%$ no CEL. Os resultados indicam, portanto, que as crenças que o professor de línguas mantém, ao se manifestarem em sua prática e gerarem determinadas experiências de aprendizagem, exercem forte influência sobre as crenças - e, consequentemente, sobre as atitudes - de seus alunos perante a aprendizagem. Nesse sentido, para conseguir mudar a crença detectada em grandes proporções entre os aprendizes da escola alemã e do CEL, é imprescindível gerar mudanças na prática vivenciada por eles nas aulas de alemão; é preciso oferecer-lhes experiências de aprendizagem que levem a uma reflexão e a uma revisão das crenças.

Cabe, por fim, ponderar que na graduação a atribuição de uma importância maior ao estudo da gramática é justificável, devido aos objetivos de aprendizagem que, conforme identifica uma das informantes deste contexto em sua entrevista, são distintos daqueles presentes nos outros contextos:

C. (graduação): Apesar de que aqui nós estamos nos formando para sermos professores, né? Então a gente tem que saber a gramática de cabo a rabo, saber como funciona, quais são os tipos de exercícios, tudo. Mas em uma aula de língua em uma escola, ou em outro contexto, eu acho que a gramática tem que ser assim... 20\% do que é a língua, 25\%. É a base, claro, mas você tem que focar em outras coisas, competências linguísticas. 
SCHÄFER, A. C. - A gramática alemã sob a perspectiva de seus aprendizes

De um curso universitário, no qual os aprendizes de língua alemã são futuros linguistas e professores da língua que estão aprendendo, espera-se, de fato, uma tematização mais detalhada e profunda (desde que também mais reflexiva) dos fenômenos gramaticais. As razões disso são evidentes: para ensinar a alguém como funcionam os mecanismos de uma língua é necessário conhecê-los a fundo. Um dos aprendizes do CEL também reconhece essa diferença quando diz, em sua entrevista, que "gramática é mais importante para quem quer se especializar".

\section{3 "Aprender gramática é sinônimo de decorar regras"}

Um dos objetivos do questionário aplicado durante a pesquisa foi levantar as estratégias utilizadas pelos informantes para aprender gramática. As três estratégias mais citadas em cada contexto estão enumeradas na tabela abaixo ${ }^{9}$ :

\begin{tabular}{cccc}
\hline Estratégias & Graduação & Escola alemã & CEL \\
\hline $\mathbf{1}^{\mathbf{0}}$ & $\begin{array}{c}\text { Fazer exercícios de } \\
\text { fixação (40\%) }\end{array}$ & $\begin{array}{c}\text { Fazer exercícios de } \\
\text { fixação (54\%) }\end{array}$ & $\begin{array}{c}\text { Fazer exercícios de } \\
\text { fixação (46\%) }\end{array}$ \\
$\mathbf{2}^{\mathbf{0}}$ & $\begin{array}{c}\text { Utilizar as estruturas } \\
\text { em exemplos (24\%) }\end{array}$ & $\begin{array}{c}\text { Decorar regras } \\
\text { isoladas (23\%) }\end{array}$ & $\begin{array}{c}\text { Decorar regras } \\
\text { isoladas (23\%) }\end{array}$ \\
$\mathbf{3}^{\mathbf{0}}$ & $\begin{array}{c}\text { Observar as estruturas } \\
\text { em seu uso (11\%) }\end{array}$ & $\begin{array}{c}\text { Pesquisar no livro } \\
\text { didático (23\%) }\end{array}$ & $\begin{array}{c}\text { Reler anotações de } \\
\text { aula (16\%) }\end{array}$ \\
\hline
\end{tabular}

Tabela 2: Estratégias utilizadas para aprender gramática

Duas coisas chamam a atenção na tabela assim estruturada. Primeiramente, o fato de, nos três contextos, a estratégia mais citada pelos aprendizes ter sido "fazer exercícios de fixação". Sob exercícios de fixação entende-se, no geral, atividades que repetem o uso de determinada estrutura com pequenas variações. Um exemplo típico são os exercícios estruturais do tipo pattern drills. Estes também remetem a um método antigo no ensino

\footnotetext{
${ }^{9}$ Tabela organizada a partir da tabulação das respostas à questão aberta "O que você faz para aprender a gramática da língua alemã"? As porcentagens entre parênteses correspondem ao percentual de alunos que citou a referida estratégia em sua resposta.
} 
SCHÄFER, A. C. - A gramática alemã sob a perspectiva de seus aprendizes

de LE: o método audiolingual, segundo o qual a aprendizagem se dá pela repetição de comportamentos.

Outro dado que salta aos olhos é a preferência dos alunos da escola alemã e do CEL pela memorização de regras isoladas (essa foi a segunda estratégia mais mencionada pelos aprendizes desses contextos em suas respostas). Tal técnica contradiz os postulados mais recentes da didática de LE, que propõem uma aprendizagem indutiva, contextualizada e focada no uso. As estratégias "utilizar as estruturas em exemplos" e "observar as estruturas em seu uso autêntico", apontadas pelos aprendizes da graduação, são, dentre as estratégias citadas na tabela, as mais condizentes com essas propostas.

Esses resultados vão ao encontro da constatação de YANG (1999), que comprovou em seu estudo a existência de uma correlação entre as crenças estruturalistas e a resistência ao uso de estratégias prático-funcionais (cf. YANG 1999: 528). Nesse sentido, um aluno que acredita na aprendizagem de línguas como sinônimo de aprender uma nova gramática evitaria estratégias como assistir a filmes, ouvir músicas e ler livros na língua-alvo e daria preferência ao estudo descontextualizado das regras gramaticais. As estratégias prático-funcionais são, entretanto, importantes para o sucesso da aprendizagem, já que, através dela, os alunos aumentam sua exposição à língua estrangeira fora da sala de aula.

A relação entre crenças e estratégias também é abordada por BENSON \& LOR (1999). Segundo os autores, se o aprendiz acredita que a melhor maneira de aprender uma língua estrangeira é “decorar” palavras e regras gramaticais, ele adotará um conjunto de estratégias voltadas para a memorização e treino repetitivo. Por outro lado, se ele acredita que a melhor forma de aprender é absorver a língua em contextos autênticos, terá atitudes positivas em relação à comunicação com falantes nativos e estará disposto a adotar estratégias sociais e comunicativas (cf. BENSON \& LOR 1999: 459).

$\mathrm{Na}$ época em que foram coletados os dados, os alunos da escola alemã estavam em fase de preparação para um exame de proficiência e demonstravam, durante as aulas, grande preocupação em cometer erros gramaticais que os impedissem de obter o certificado. Esse receio, somado à urgência de internalizar estruturas gramaticais, parece ser um dos fatores que os fazia optar pela aprendizagem mecânica da gramática. 
SCHÄFER, A. C. - A gramática alemã sob a perspectiva de seus aprendizes

Entretanto, para se comprovar, essa relação precisaria ser investigada mais a fundo em trabalhos futuros.

Já no CEL, os resultados parecem estar ligados às experiências do ensino regular de línguas estrangeiras em grande parte escolas públicas brasileiras. As salas de aula lotadas, a falta de materiais e o curto espaço destinado às aulas de LE no currículo escolar - dentre outros fatores - dificultam a introdução de alguma abordagem que não seja a mais tradicional, pautada nas aulas frontais, no ensino descontextualizado de regras gramaticais e exercícios de tradução. Ao ingressarem nos cursos de idiomas paralelos do CEL, os aprendizes trazem em suas crenças marcas da tradição vivenciada no ensino regular, bem como as estratégias que utilizam naquele contexto.

Em ambos os casos, mostra-se novamente a necessidade de se mudar a prática para, assim, abrir caminhos para a mudança de crenças.

\section{Discussão dos resultados e implicações didáticas}

Ao comparar os resultados dos três contextos em que foi desenvolvida a pesquisa, é possível perceber que, enquanto entre os alunos de graduação, as crenças acerca da aprendizagem de gramática estão mais ancoradas nos preceitos recentes da didática de LE, grande parte dos aprendizes da escola alemã e do CEL ainda mantêm concepções ligadas às abordagens mais antigas (sobretudo ao método de gramática e tradução). Tal diferença pode ser atribuída ao fato de, na graduação, o estudo da língua estrangeira ser transpassado o tempo todo por reflexões metalinguísticas e didáticas, visto que, ao fim do curso, os estudantes devem se tornar especialistas na língua que estão aprendendo.

Esses resultados sugerem que um possível caminho para reverter as crenças identificadas entre os alunos da escola alemã e do CEL esteja, de fato, em uma abordagem mais profunda e reflexiva dos fenômenos gramaticais, que não se restrinja ao estudo repetitivo de regras isoladas. Para que essa mudança nas crenças seja possível não basta, entretanto, dizer aos alunos que é inútil decorar regras gramaticais descontextualizadas. É necessário mostrar aos aprendizes que existem caminhos mais eficientes para se chegar aos objetivos que eles têm, criar oportunidades para que experimentem novas estratégias de aprendizagem. Conforme observa SCHRAMM (2008: 95, grifo nosso), 
SCHÄFER, A. C. - A gramática alemã sob a perspectiva de seus aprendizes

[...] crianças, adolescentes e adultos que querem melhorar suas competências em língua estrangeira podem aumentar a eficácia de sua aprendizagem lançando mão de estratégias escolhidas de acordo com cada meta linguística a ser atingida e que estejam de acordo com seus estilos cognitivos individuais.

Um dos modelos teóricos que mostra caminhos para a transmissão de estratégias de aprendizagem é o Cognitive Academic Language Learning Approach (CALLA) de Chamot \& O’MAlley (1994). Ele é composto de três fases, durante as quais o protagonismo na aprendizagem é transmitido gradualmente do professor aos aprendizes, como ilustra a figura a seguir:

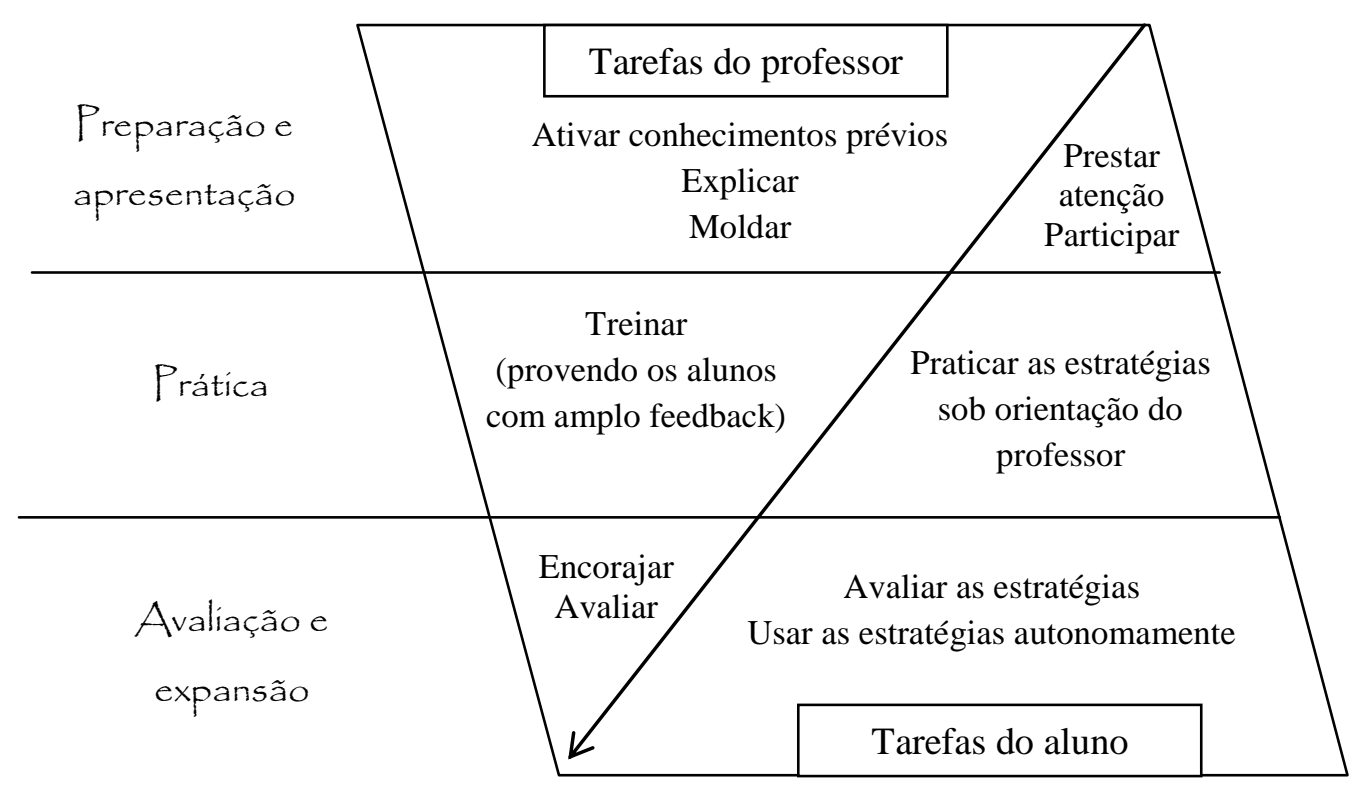

Figura 1: Modelo CALLA, CHAMOT \& O’MALLEY (1994 apud SCHRAMM 2008: 103)

Na primeira fase, de preparação e apresentação, o professor ativa o conhecimento prévio dos alunos e introduz uma nova estratégia, que é esclarecida e exemplificada a partir de exemplos. Para ativar o conhecimento estratégico e as experiências prévias do aprendiz pode-se utilizar, por exemplo, questionários, diários de aprendizagem, discussões em grupo ou na classe. Nesse estágio, é fundamental deixar claro para quais metas específicas cada estratégia pode ser usada.

A segunda fase destina-se à transformação do conhecimento declarativo em conhecimento procedural. Nela, o aluno pratica a estratégia. Essa treino deve ser 
SCHÄFER, A. C. - A gramática alemã sob a perspectiva de seus aprendizes

moderado por um utilizador de estratégias competente, função didática que pode ser assumida por um colega, pelo material didático ou pelo professor.

$\mathrm{Na}$ terceira e última fase, devem ser feitas a avaliação das estratégias e a expansão de seu uso. Isso pode ser feito novamente através listas de checagem, diários de aprendizagem ou discussões. Depois de avaliar a eficácia das estratégias, os aprendizes decidem quais delas querem incorporar de fato a seu repertório. Essa última fase é especialmente importante para o uso consciente de estratégias de aprendizagem. Os professores devem incentivar seus alunos não só a cumprir as atividades propostas, mas também a refletir sobre os meios que foram utilizados para se chegar ao resultado.

Grande parte dos livros didáticos recentes para ensino de alemão como língua estrangeira transmitem estratégias de aprendizagem. Em alguns deles, a transmissão é feita de forma implícita e inconsciente (blind training) em meio aos exercícios e atividades propostas. É esse o caso dos livros didáticos utilizados na graduação (Schritte International, HILPERT 2009) e na escola alemã (AusBlick, FISCHERMITZIVIRIS 2010). Outros, porém, possuem seções voltadas especialmente para a aprendizagem consciente e reflexiva de estratégias. É o caso do livro didático Planet (KOPP \& BÜTTNER 2012), utilizado no CEL. A cada duas lições, há uma seção denominada Lernen lernen (em português: aprender a aprender), na qual são apresentadas coletâneas de estratégias de aprendizagem que podem ser testadas pelo aprendiz ao estudar os conteúdos das lições anteriores.

Além de estimular o desenvolvimento do conhecimento procedural, grande parte dos materiais didáticos atuais traz atividades que promovem uma aprendizagem indutiva dos conteúdos gramaticais. Seguindo os preceitos do método intercultural, geralmente parte-se de um texto onde o fenômeno gramatical a ser abordado aparece com frequência. Depois de os aprendizes terem compreendido o conteúdo geral do texto, passam a analisar as estruturas em seu uso autêntico e a depreender daí seu funcionamento.

Nos livros didáticos recentes, a gramática também costuma ser apresentada e treinada como base da comunicação. Nas atividades concebidas com esse objetivo, o tópico gramatical é apresentado no contexto de uma ação comunicativa que necessita dele para se realizar. Assim, os aprendizes são convidados a utilizar o conteúdo novo para concretizar uma determinada intenção comunicativa. 
SCHÄFER, A. C. - A gramática alemã sob a perspectiva de seus aprendizes

Alguns tópicos da gramática alemã são especialmente propícios a uma aprendizagem reflexiva, que tenha como objetivo a conscientização linguística. LUCHTENBERG (2008: 113) destaca o campo da formação de palavras como rica fonte de atividades para esse tipo de abordagem. A formação dos substantivos compostos em alemão seria, segundo a autora, um tema especialmente apropriado para a reflexão sobre a língua para a consequente desmistificação - feita preferencialmente de forma lúdica desse tópico da gramática alemã, conhecido pelas "palavras quilométricas" que tanto assustam os aprendizes.

Krumm (2010: 864), por sua vez, cita o uso de procedimentos da linguística contrastiva na aula de LE como meio de se refletir sobre o funcionamento da língua. Nas palavras do autor, para as abordagens de language awareness, a reflexão consciente sobre a nova língua pode sempre ser estimulada através do contraste das formas da língua-alvo com as da língua materna.

Há, enfim, diversos meios de o professor atuar sobre as crenças de seus aprendizes e promover uma abordagem reflexiva e contextualizada dos conteúdos gramaticais. Se bem utilizados, os recursos oferecidos pelo próprio livro didático podem contribuir para a desconstrução de certas crenças acerca da gramática alemã, potencialmente nocivas ao processo de aprendizagem.

\section{Considerações finais}

Os resultados de pesquisa divulgados neste artigo revelam que os aprendizes de alemão constroem verdadeiras teorias subjetivas (cf. KALLENBACH 1996) sobre a aprendizagem dessa língua, as quais não devem ser ignoradas pelo professor. As crenças dos aprendizes são parte fundamental dessas teorias e, como tal, exercem influência positiva ou negativa - sobre o processo de aprendizagem de cada um deles. Como sugeriram os dados apresentados, certas crenças podem, por exemplo, restringir o uso de estratégias de aprendizagem e provocar desmotivação.

Quando uma crença pode constituir obstáculos à aprendizagem, a aula de LE deve buscar meios de contribuir para sua desconstrução. Para que a mudança seja possível, faz-se necessário primeiramente explicitar as crenças do aprendiz, tornando-as passíveis de análise e reflexão. Isso pode ser feito, como sugere BARCELOS (2007: 131), 
SCHÄFER, A. C. - A gramática alemã sob a perspectiva de seus aprendizes

através de atividades simples, como narrativas individuais sobre as próprias experiências de aprendizagem e discussões em pequenos grupos. $\mathrm{O}$ ponto de partida para as conversas pode estar em textos que estimulem a reflexão dos alunos sobre suas crenças. O relato do escritor Mark Twain sobre a dificuldade da língua alemã é, por exemplo, bastante apropriado como impulso para esse tipo de atividade.

Para atuar sobre as crenças é também imprescindível que se ceda espaço nas aulas para os alunos tomarem contato e testarem novas estratégias de aprendizagem. Os materiais didáticos atuais são dotados de recursos que poderiam ser amplamente utilizados na desmistificação da língua alemã e na desconstrução de diversas crenças. Entretanto, esse potencial é frequentemente desperdiçado, quando os professores muitas vezes pressionados pelo cronograma institucional - deixam de lado atividades que exigem maior reflexão sobre o processo de aprendizagem, contrariando, assim, a constatação de BARCELOS (2007: 131), segundo quem hoje em dia

[...] a sala de aula não é somente o lugar para se aprender língua materna ou estrangeira. É também o lugar para se aprender a pensar sobre a aprendizagem ou sobre fatores desse processo, como as crenças, os estilos e as estratégias de aprendizagem e suas mudanças.

A importância de trabalhos que tematizam as crenças de aprendizes se justifica por diversos motivos, enumerados por BARCELOS (2007: 112). O estudo das convicções do aprendiz permite, em primeiro lugar, que o professor compreenda as atitudes de seus alunos durante o processo de aprendizagem da língua alemã. Da mesma forma, o conhecimento das crenças auxilia o professor na seleção e implementação de determinadas abordagens, administrando possíveis conflitos entre estas e as expectativas dos alunos. A pesquisa nessa área pode ainda contribuir para a compreensão da relação entre crenças de professores e alunos e para a reflexão acerca do processo de ensino/aprendizagem nos cursos de formação de professores.

Cabe relembrar que, como destaca CAVALCANTI (2009: 180), a escolha de temas de pesquisa na área de ensino/aprendizagem de línguas deve ser guiada preferencialmente pela identificação de obstáculos à prática pedagógica. Quando se transformam problemas práticos em problemas de pesquisa, a pesquisa traz retorno à própria prática. Foi este, enfim, o caminho que o presente estudo buscou seguir ao se debruçar sobre as crenças de aprendizes de alemão como língua estrangeira, identificar 
SCHÄFER, A. C. - A gramática alemã sob a perspectiva de seus aprendizes

efeitos negativos de algumas delas sobre a aprendizagem e, finalmente, apontar recursos didáticos que permitem uma abordagem consciente e reflexiva das crenças em sala de aula. Como perspectiva de trabalhos futuros, apresenta-se, por fim, a investigação empírica de como a implementação de modelos didáticos recentes para o ensino de gramática contribui, na prática, para a mudança de crenças específicas e de como as crenças de um mesmo aprendiz variam ao longo de seu percurso de aprendizagem.

\section{Referências bibliográficas}

Almeida Filho, J. C. P. Dimensões Comunicativas no Ensino de Línguas. Campinas, Pontes, 1993.

BARCElos, Ana Maria Ferreira. A cultura de aprender línguas (inglês) de alunos no curso de letras. In: ALMEIDA FILHO, José Carlos de (Org.). O professor de língua estrangeira em formação. Campinas, Pontes, 2009, 157 -177.

BARCELOS, Ana Maria Ferreira. Reflexões acerca da mudança de crenças sobre ensino e aprendizagem de línguas. In: Revista Brasileira de Linguística Aplicada, 7 (2), 2007, 109-138.

BARCELOS, Ana Maria Ferreira. Metodologia de pesquisa das crenças sobre aprendizagem de línguas: Estado-da-arte. Revista Brasileira de Linguística Aplicada, Belo Horizonte, v. 1, n. 1, 2001, p. 71-92.

BAUER, Ulrich. "Ist Deutsch eine "schwere" Sprache? Linguistische Bemerkungen zur typologischen Distanz Deutsch-Spanisch und der vorwissenschaftlichen Beurteilung des Deutschen". In: DaF - Brücke, 5, 2003, 4-7.

BENSON, Phil \& LOR, Winnie. Conceptions of language and language learning. In: System, 27, 1999, 459-472.

BoHUNOVSKY, Ruth. Imagens de uma língua: reflexões sobre o ensino de alemão como língua estrangeira no Brasil. In: Pandaemonium Germanicum, 9, 2005, 327, 344.

Brasil. Ministério Da EdUCAÇÃo E Do DesPorto. Parâmetros Curriculares Nacionais Ensino Médio - Linguagens, Códigos e suas Tecnologias. Brasília, Secretaria de Educação Média e Tecnológica, 1999.

CAVAlCANTI, Marilda do Couto. Reflexões sobre a prática como fonte de temas para projetos de pesquisa para a formação de professores de LE. In: ALMEIDA FILHO, José Carlos de (Org.). O professor de língua estrangeira em formação. Campinas, Pontes, 2009, 179184.

ChAmot, Anna \& O'MALLEY, J. Michael. The CALLA Handbook. Implementing the Cognitive Academic Language Learning Approach. New York, Longman, 1994.

CONSElHo DA EUROPA. Quadro Europeu Comum de Referência para Línguas. Porto, Asa Editores, 2001.

COTTERALl, Sara. Readiness for autonomy: investigating learner beliefs. In: System, 23 (2), 1995, 435-441.

DÖRNYEI, Zóltan. Learner Beliefs. In: The Psychology of the Language Learner: Individual Differences in Second Language Acquisition. New Jersey, Lawrence Erlbaum Associates, 2005, 214-217. 
SCHÄFER, A. C. - A gramática alemã sob a perspectiva de seus aprendizes

GARDNER, Gardner, R. C. Social Psychology and Second Language Learning: The Role of Attitudes and Motivation. London, Edward Arnold, 1985.

GöTZE, Lutz. Linguistische und Didaktische Grammatik. In: HELBIG, Gerhard. Deutsch als Fremdsprache: Ein Internationales Handbuch. Berlim, De Gruyter, 2001, 187-194.

HoRwITZ, Elaine. The Beliefs about Language Learning of Beginning University Foreign Language Students. In: The Modern Language Journal, 72 (3), 1988, 283-294.

Kallenbach, Christiane. Subjektive Theorien: was Schüler und Schülerinnen über Fremdsprachenlernen denken. Tübingen, Narr Verlag, 1996.

KRUMM, Hans-Jürgen et al. Sprachbewusstheit und Sprachlernbewusstheit. In: Deutsch als Fremd- und Zweitsprache. Ein internationales Handbuch. Berlim, De Gruyter Mouton, 2010, 858-866.

LEFFA, Vilson J. A look at students' concept of language learning. In: Trabalhos em Linguística Aplicada, 17, 1991, 57-65.

Luchtenberg, Sigrid. Language Awareness. In: Ahrenholz, Bernt \& OOME-Welke, Ingelore (Org.). Deutsch als Zweitsprache. Baltmannsweiler, Schneider Verlag, 2008, 107-117.

MicCOLI, Laura. Experiências, crenças e ações: uma relação estreita na sala de aula de LE. In: SILVA, Kleber Aparecido da (Org.). Crenças, Discursos \& Linguagem. Campinas, Pontes Editores, 2010, 135-165.

NEUNER, Gerhard \& Hunfeld, Hans. Methoden des fremdsprachlichen Deutschunterrichts. Eine Einführung. Berlim, Langenscheidt, 1993.

RozenfEld, Cibele C. F. \& VianA, Nelson. O desestranhamento em relação ao alemão na aprendizagem do idioma: um processo de aproximação ao "outro" sob a perspectiva da competência intercultural. In: Pandemonium Germanicum, 17, 2011, 259-288.

SCHRAMM, Karen. Sprachlernstrategien. In: AHRENHOLZ, Bernt \& OOME-WeLKE, Ingelore (Org.). Deutsch als Zweitsprache. Baltmannsweiler, Schneider Verlag, 2008, 95-106.

SPANNHAKE, Barbara \& BoGACZ-GROB, Agnieszka. Grammatik im DaZ-Unterricht. In: Kaufmann, S. et al. Fortbildung für Kursleitende Deutsch als Zweitsprache. Band 2: Methodik und Didaktik. Ismaning, Hueber, 2008, 234-275.

TwAIN, Mark. Bummel durch Europa (Trad. Ana Maria Brock). Berlim, Aufbau-Verlag, 1985.

YANG, Nae-Dong The relationship between EFL learners' beliefs and learning strategy use. In: System, 27, 1999, 515-535.

\section{Materiais didáticos citados no texto}

FISCHER-MITZIVIRIS, Anni. AusBlick. Deutsch für Jugendliche und junge Erwachsene. Deutsch als Fremdsprache. Ismaning, Hueber, 2010.

HILPERT, Silke et al. Schritte International. Deutsch als Fremdsprache. Ismaning, Hueber, 2009.

KoPP, Gabriele \& BüTTNER, Siegfried. Planet. Deutsch für Jugendliche. Ismaning, Hueber, 2012. 